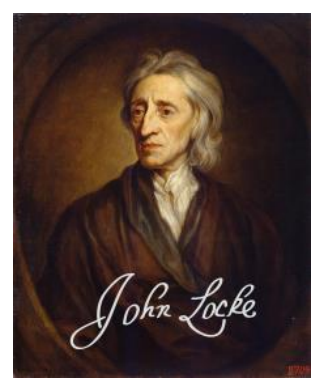

LOCKE STUDIES

Vol. 14

https://doi.org/10.5206/ls.2014.720 | ISSN: 1476-0290

Originally published: 2014

Published online: 19 FEBRUARY 2018

(C) Locke Studies, 2014

\title{
Locke on the 'Species' of Substances
}

\author{
JESSE NEWTON (JAMES MADISON UNIVERSITY)
}

Recommended citation:

Newton, Jesse. "Locke on the 'Species' of Substances." Locke Studies 14 (2014): 105-120.

https://doi.org/10.5206/ls.2014.720

For more information about this article:

https://ojs.lib.uwo.ca/index.php/locke/article/view/720

Locke Studies is published by The John Locke Society.

This is an open access article published under the terms of the Creative Commons Attribution-

NonCommercial-ShareAlike 4.0 International license, which permits use, distribution and reproduction in any medium, provided the original work is properly cited and shared under the original license. 


\title{
LOCKE ON THE ‘SPECIES’ OF SUBSTANCES
}

\author{
JESSE NEWTON
}

\section{Introduction}

Locke's treatment of species has received considerable attention in recent years. It is generally agreed that he rejects species realism-the view that the species of substances exist independently of human thought and language - and defends a modest conventionalism. He accepts that natural similarities exist between objects, but denies that they produce one unique and best system of classification; that is, he denies that they carve nature at its joints. Rather, our systems of classification are matters of human interest and convention that take their 'occasion from the similitude' we observe in things. ${ }^{1}$ Thus, whether an animal is, say, a bird, is a reflection of whether we have decided to classify it as such (based on certain similarities we observe) and not because it is a member of a natural species bird that exists independently of human thought and language.

While it hard to overstate the importance of Locke's conventionalism, the majority of recent scholarship has concentrated almost exclusively on the ontological implications of his attacks against species. No doubt, these are quite interesting to modern scholars, since they bear a strong similarity to many contemporary issues about classification and natural kinds; however, they were not Locke's only concerns. He pursues several other independent lines of argument alongside his defence of species conventionalism. One such concern is to demonstrate that our actual systems of classifications are poorly constructed and do not mirror natural species; this is true whether or not any real species happen to exist. This claim appears to have been of some importance to Locke; however, it has received very little

${ }^{1}$ John Locke, An Essay concerning Human Understanding, ed. P. H. Nidditch (Oxford, 1975), III. iii. 13, 415. 
attention in the literature. This is unfortunate. Not only has it led to an incomplete picture of his discussion of species, but it has produced an inaccurate one as well: quite often the arguments for this weaker claim are not always clearly distinguished from Locke's more substantive attacks against species realism.

Part of the reason for this is because Locke does not carefully and clearly distinguish them. He slides back and forth between the two, and, even more confusingly, uses similar terminology in both. Throughout his discussion of substance terms Locke employs 'species' in an ambiguous fashion. Sometimes he uses it to refer to natural species, while at other times he uses it only to refer to our actual, de facto classifications. This makes interpreting him correctly extremely complicated since some arguments against the weaker thesis could just as easily be interpreted as arguments against the more substantive ontological one, and vice versa.

The aim of this paper is to better distinguish these two lines of argument. I argue that Locke restricts his use of 'species' to refer our actual, de facto classifications through the use of specific qualifying terms and phrases. These are used in order to alert the reader when he is shifting focus away from his more substantive ontological conclusions. While what I argue has implications for his arguments against natural species, my paper does not attempt to weigh in on this issue directly. Its primary purpose is clarificatory: to help distinguish, and avoid confusing, different lines of argument in Locke. Doing this helps to free us from certain confusions that sometimes arise in reading Locke.

\section{Locke's Use of 'Species'}

There are at least two important types of questions concerning classification that interest Locke in his discussion of species. ${ }^{2}$ First, there is the ontological question of classification. This

\footnotetext{
${ }^{2}$ For helpful discussions see Nicholas Jolley, Leibniz and Locke: A Study of the New Essays on Human Understanding (Oxford, 1984), 145ff; R. S. Woohouse, Locke's Philosophy of Science and Knowledge (New York, 1971), $115 \mathrm{ff}$.
} 
concerns whether or not natural species exist. Secondly, there is the de facto question of classification. This concerns the extent to which our ordinary, linguistic classifications correspond with natural species. There is, at best, a one-way entailment between answers to these two types of questions. If, for example, natural species do not exist, then our actual systems of classifications cannot be based upon them. However, the reverse is not true. For it may be possible that natural species exist, but also be the case that our de facto classes do not (and possibly cannot) resemble them.

While commentators more often discuss the ontological question of classification, ${ }^{3}$ there are passages where one must assume that Locke is discussing only the de facto question. An obvious example occurs in An Essay concerning Human Understanding, III. vi. 25, when he responds to the worry that the real essences of things might someday be discovered. ${ }^{4}$ This argument continues a longer line of thought which purports to establish that the several sorts of substances are not distinguished according to their real essences. Locke argues that since the real essences of things were never considered by the greatest part of men they cannot be the basis of classification (III. vi. 24). He then argues that even if such a discovery were made it would prove irrelevant 'since Languages, in all Countries, have been established long before Sciences' (III. vi. 25). He continues:

So that they have not been Philosophers, or Logicians, or such who have troubled themselves about Forms and Essences, that have made the general Names, that are in use amongst the several Nations of Men: But those, more or less comprehensive terms, have, for the most part, in all Languages, received their Birth and Signification, from ignorant and illiterate People, who sorted and denominated Things, by those sensible Qualities they found in them, thereby to signify them, when absent, to

\footnotetext{
${ }^{3}$ Ibid.

${ }^{4}$ Essay, III. vi. 25, 452-53.
} 
others, whether they had an occasion to mention a Sort, or a particular Thing.

Clearly Locke's argument is not concerned with the ontological status of natural species. After all, what bearing would the linguistic practices of 'ignorant and illiterate People' have on them? The argument being made here is that our linguistic classes are not determined on the basis of real essences since those who first coined the terms of ordinary language were ignorant of these. Instead, the meanings of these terms are determined only on the basis of various observable qualities. As a result, the meanings of ordinary terms cannot be affected by a discovery of these real essences. ${ }^{5}$ To alter their meanings in light of such a discovery would fundamentally change how they are usually understood and so subvert the basic purpose of language, namely, communication.

This is not the only argument in which Locke focuses on the de facto question of classification. There are others; however, these are not always properly distinguished from those passages in which Locke is focused on the ontological question of classification. Part of the reason for this is that Locke uses the term 'species' ambiguously throughout his discussion of general terms.

In Locke's day (as well as ours) the term 'species' was used in a variety of ways. The original meaning of 'species' was 'appearance' or 'outward form', and in the scholastic and early modern period, it was often used to refer to concepts and ideas. Locke is clearly familiar with this usage. ${ }^{6}$ It is, however, unlikely that he uses it in this way in Book III of the Essay. He says that

${ }^{5}$ One may think (and many have complained with Locke on this score) that we could simply refine our pre-theoretic classifications in the wake of scientific discovery. (For instance, the term 'fish' was used to refer to whales prior to discovering that they had lungs.) Locke says this is certainly possible; however, he thinks by doing this one runs the risk of being misunderstood.

${ }^{6}$ Essay, I. i. 8, 47. 
'species' and 'sort' are perfectly synonymous. ${ }^{7}$ Locke, therefore, uses it in a way more familiar to us, to refer to groups of things. Yet even here his meaning can be unclear. The term 'species' is sometimes employed in a strong, ontologically loaded sense. According to this, a species is a mind-independent and ontologically privileged class of things. It is precisely in this sense that the term is used in modern discussions of natural kinds. However, 'species' is also sometimes used in an ontologically innocent way. In logic, for instance, 'species' simply refers to a subclass within a larger class of things. Likewise, in ordinary discourse we might sometimes say things such as 'no species of artist is as praised as the actor'. In both instances, no assumption of ontological privilege is made. ${ }^{8} \mathrm{~A}$ 'species' in this ontologically innocent sense only refers to a group of things that share a common attribute and are referred to by a common name.

Some scholars assume that Locke uses 'species' exclusively in the strong, ontologically loaded sense. ${ }^{9}$ This cannot be correct. Locke employs 'species' in a wide variety of contexts. He uses the term indiscriminately to speak of the 'species' of simple ideas, ${ }^{10}$ mixed modes, ${ }^{11}$ and even artificial things. ${ }^{12}$ Yet not all of these categories constitute natural kinds. Artifacts clearly do not. Neither do the 'species' of mixed modes. After all, Locke says that murder is a different 'species' from stabbing (III.v.6). And quite obviously neither of these forms a natural kind.

${ }^{7}$ Essay, III. v. 9, 434.

${ }^{8}$ Whether or not such an assumption is made is determined by the speaker's intention.

${ }^{9}$ For instance, Nigel Leary, 'How Essentialists Misunderstood Locke,' History of Philosophy Quarterly 26, (2009): 273-92, writes (at 276), 'Locke uses the terms 'genus,' 'species,' and 'sort,' which can all be treated as synonyms for 'natural kind'.

${ }^{10}$ Essay, III. iv. 16, 427.

${ }^{11}$ Essay, III. v, 428-38.

${ }^{12}$ Essay, III. vi. 40, 464. 
Perhaps it is more plausible to claim that in his discussion of substances, specifically, Locke uses 'species' exclusively (or at least primarily) in the ontologically loaded sense. Something like this appears to be the accepted wisdom. However, little justification, if any, is ever given for this assumption. And it seems questionable. I argue that many cases where it is common to assume Locke is referring to natural species, he is in fact using 'species' in an ontologically innocent sense. On these occasions Locke employs 'species' to refer to our ordinary linguistic classifications. He does so in order to argue that our ordinary linguistic groups (or de facto species) do not mirror those established by nature. This conclusion follows whether or not any such species exist in nature and can be established independently of answers to the ontological question of classification.

Locke provides a number of textual cues in order to indicate to the reader when he is using 'species' in this ontologically innocent sense. These are often overlooked. To better recognize them it is helpful to consider one of his earlier writings where he more clearly distinguishes natural and de facto species.

In a journal entry dated November 19, 1677 Locke writes the following.

our Ideas of species are almost voluntary or at least different from the Idea of nature by which she forms and destinguishes them, which in animals she seems to me to keepe to with more constancy and exactness than in other bodys and species of things [...soe that] species in respect of us are but things ranked into orders because of their agreement in some ideas which we have made essentiall in order to our nameing. Though what is to be essentially belong[ing] to any species in reference to nature be hard to determin. ${ }^{13}$

In order to fully understand this passage it is important keep in mind that at this stage in Locke's career he held views at odds

${ }^{13}$ See An Early Draft of Locke's Essay, together with Excerpts from his Journals, ed. R. I. Aaron and Jocelyn Gibb (New York, 1936), 98-99, my underlining. 
with those that he would later expound in the Essay. In particular, at this point he endorsed the existence of natural species. He held that they are maintained by the order of generation. ${ }^{14}$ This establishes clear and natural boundaries between species. However, as we see here, Locke argues that we lack precise ideas of these boundaries. In his terms, 'our Ideas of species' are 'different from the Idea of nature by which she forms and destinguishes' species. ${ }^{15}$ Locke then puts this contrast differently, drawing a distinction of his own between 'species in respect of us' and 'species in reference to nature.' The former are made according to our ideas for the purpose of naming; we establish what is essential to them. The latter, on the other hand, are not made according to our ideas: they are made according to the 'Idea of nature.' What is essential to them is 'hard to determin'. It seems reasonable to suppose, given this context, that 'species in respect of us' are our actual, de facto classifications. These are species for which we have names. 'Species in reference to nature,' however, are natural species. And Locke's point is that our de facto species do not mirror natural species because the ideas by which we form these species are actively made by the mind according to our various needs and purposes.

It is important to note how natural species are distinguished from de facto species. Locke uses two distinct qualifying phrases. He refers to natural species as species 'in reference to nature,' while he refers to de facto species as species 'in reference to us.' De facto species are specified by affixing a first-person qualifier, 'to us,' to 'species'. This is done deliberately in order to let the reader know that Locke is not discussing natural species per se,

${ }^{14}$ See Locke's journal entry for September 19, 1676, in An Early Draft, 83. There he explicitly states that nature keeps things in 'distinct classes by the order of generation'. While the 1677 passage is written over a year later, its opening is taken almost line for line from the 1676 passage, and in the section in parentheses which I omit Locke reiterates his belief that natural classes are maintained by generation.

${ }^{15}$ In referring to the 'Idea of nature' Locke is anthropomorphizing nature. All he means is that there are prefixed boundaries established by nature. 
but instead just those sorts of classes that are dependent upon our interests and linguistic conventions. The species 'to us' do not mirror species 'in nature.' Similar language is used in the Essay. Consider the following passage from III. vi. 30:

[The] Boundaries of species, are as Men, and not as Nature makes them, if at least there are in Nature any such prefixed Bounds. 'Tis true, that many particular Substances are so made by Nature, that they have agreement and likeness one with another, and so afford a Foundation of being ranked into sorts. But the sorting of things by us, or the making of determinate Species, being in order to naming and comprehending them under general terms, I cannot see how it can be properly said, that Nature sets the Boundaries of the Species of Things: Or if it be so, our Boundaries of Species, are not exactly conformable to those in Nature (emphasis mine).

Both at the start of the passage ('if at least there are in Nature') and at the end ('or if it be so') Locke concedes the possibility that natural species may exist. Granted, he appears quite skeptical of this. But he does not push this skepticism. The argument being made is that even if natural species exist, our de facto classifications do not accurately describe them. Like in his journal entry, Locke indicates de facto species through the use of a firstperson qualifier. Here he uses two: sorting 'by us' and 'our' boundaries. These are distinguished from species boundaries 'in Nature'.

Locke's use of these first-person qualifiers is markedly different from the way he writes on other occasions:

Nor let any one say, that the power of propagation in animals by the mixture of Male and Female, and in Plants by Seeds, keeps the supposed real Species distinct and entire. For granting this to be true, it would help us in the distinction of the Species of things no farther than the Tribes of Animals and Vegetables. What must we do for the rest? But in those too it is not sufficient: for if History lie not, Women have conceived by Drills; and what real Species, by that measure, such a Production will be in Nature, will be a new Question ${ }^{16}$

${ }^{16}$ Essay, III. vi. 23, 451. 
It is clear that this passage addresses natural species; Locke refers to them simply as 'real Species'. There is no mention of linguistic practices or names; nor does Locke invoke any firstperson pronoun ('us', 'we', 'our') to qualify 'species'. There is an obvious terminological difference. This is deliberate on Locke's part. He is conscientious of the distinction between named and natural species, and alerts the reader to his shift in focus.

Locke uses other types of qualifiers to refer to de facto species. Consider again the III. vi. 25 passage.

But supposing that the real Essences of Substances were discoverable, by those, that would severely apply themselves to that Enquiry; yet we could not reasonably think, that the ranking of things under general Names, was regulated by those internal real Constitutions, or any thing else but their obvious appearances. Since Languages, in all Countries, have been established long before Sciences. ${ }^{17}$

The passage opens with the question of whether the discovery of real essences would undermine Locke's arguments against species. He then says that we could not think the ranking of things 'under general Names' is regulated by them since languages in all countries were established long before such discoveries were possible. The phrase 'under general Names' is critical. Locke uses it here to emphasize that he is not concerned with the ranking of things per se, but only the ranking of things that have been named.

That Locke deliberately draws such a distinction appears to be corroborated in his correspondence with Stillingfleet. Throughout their exchange, Stillingfleet repeatedly challenged Locke's contention that species are not established by agreement between the real essences of individuals of a given species. It is clear that Stillingfleet interpreted this as solely addressing the ontological question of classification. Time and time again Locke attempted

${ }^{17}$ Essay, III. vi. 25, 452. 
to rein Stillingfleet in, bringing the issue back to the question of species names and the formation of our abstract ideas.

Stillingfleet cites one of Locke's own illustrations, which involves how we form our general idea of the sun. ${ }^{18}$ Stillingfleet argued that when we abstract the idea of the sun, we abstracts an idea of its real essence. This real essence is what makes the sun to be what it is. It is also what makes it belong to the species it does. Moreover, anything that has a qualitatively identical real essence would belong to that same species as the sun does. Hence, our species ideas are not purely conventional; they are a product of objective similarities that exist in nature. Locke offers two responses. First, he denies that we have any idea of the sun's real essence. He then says that Stillingfleet's entire argument is misplaced because he had only been discussing named species. He adds that if he had meant to discuss the species as distinguished according to the real essences he would have said so:

Your lordship's proof here brought out of my Essay, concerning the sun, I humbly conceive will not reach it; because what is said there does not at all concern the real, but nominal essence; as is evident from hence, that the idea I speak of there, is a complex idea; but we have no complex idea of the internal constitution, or real essence of the sun. Besides, I say expressly, that our distinguishing substances into species by names, is not at all founded on their real essences. So that the sun being one of these substances, I cannot, in the place quoted by your lordship, be supposed to mean by essence of the sun, the real essence of the sun, unless I had so expressed it. ${ }^{19}$

Locke frequently uses such qualifiers to refer to de facto species. For instance, he sometimes speaks of 'Species, as we

${ }^{18}$ Essay, III. vi. 1, 439.

${ }^{19}$ John Locke, 'A Letter to the Right Rev. Edward Lord Bishop of Worcester, concerning some Passages relating to Mr. Locke's Essay of Human Understanding', in The Works of John Locke (10 vols., London, 1823), iv, 83-84. 
rank them', ${ }^{20}$ while other times he speaks of species 'as distinguished and denominated by us, ${ }^{21}$ and at other times again he speaks of species 'as apprehended, and made use of by us' ${ }^{22}$ These clauses qualify 'species' in terms of our actual linguistic practices. It seems reasonable to suppose that each of these locutions also represents ways of indicating de facto species. If this is correct, it should have a significant influence upon the way we read a number of Locke's arguments. Consider, for instance, the following argument:

The next thing to be considered is, by which of those Essences it is, that Substances are determined into Sorts, or Species; and that 'tis evident, is by the nominal Essence. For 'tis that alone, that the name, which is the mark of the Sort, signifies. 'Tis impossible therefore, that anything should determine the Sorts of Things, which we rank under general Names, but that Idea, which that Name is design'd as a mark for; which is that, as has been shewn, which we call the Nominal Essence...How comes any particular thing to be of this or that Sort, but because it has that nominal Essence, Or, which is all one, agrees to that abstract Idea, that the name is annexed to ${ }^{23}$

Locke is arguing that individuals belong to a certain species by agreeing to an abstract idea and not by possessing a certain real essence. This is demonstrated by the fact that substance terms signify only nominal, and not real, essences. This is a perplexing argument. It is especially difficult if it is assumed that Locke's intention is to show that individuals are not members of a natural species. After all, what possible ontological implications follow from facts about language use? But this is not what he is arguing. This is revealed in the fifth line (above) when Locke qualifies his

${ }^{20}$ Essay, III. x. 21, 502.

${ }^{21}$ Essay, III. iii. 13, 415, my underlining.

${ }^{22}$ Essay, III. vi. 43, my underlining.

${ }^{23}$ Essay, III. vi. 7, 443. 
sense of 'species' with the clause 'under general Names' (my emphasis). This phrase signals that Locke is not discussing species in the strong ontological sense, but only de facto species. His argument is that individuals belong to de facto species by agreeing with a nominal essence.

Consider another argument made a section later, in III. vi. 8:

And that the Species of Things to us, are nothing but the ranking them under distinct Names, according to the complex Ideas in us; and not according to precise, distinct, real Essences in them, is plain from hence; That we find many of the Individuals that are ranked into one Sort, called by one common Name, and so received as being of one Species, have yet Qualities depending on their real Constitutions, as far different one from another...Chemists...sometimes in vain, seek for the Qualities in one parcel of Sulphur, Antimony, or Vitriol, which they have found in others. For though they are Bodies of the same Species, having the same nominal Essence, under the same Name; yet they do often, upon severe ways of examination, betray Qualities so different one from another, as to frustrate the Expectation and Labour of very wary Chymists. But if Things were distinguished into Species, according to their real Essences, it would be as impossible to find different Properties in any two individual Substances of the same Species, as it is to find different Properties in any two Circles, or two equilateral Triangles.

The argument can be summarized as follows:

1. Sameness of real essence determines sameness of species. [assumed for reductio]

2. The qualities of individuals supervene on their real essences.

3. Scientists have discovered that the members of a single species often differ with respect to their qualities.

4. Hence, members must differ with respect to their real essences as well. 
5. Therefore, species membership is not determined by sameness of real essence.

6. Hence, species membership is determined on the basis of convention.

Many commentators interpret this as a rejection of natural species. ${ }^{24}$ The problem with understanding it this way is that there is no reason an advocate of natural species should accept Premise 3 . They could argue in response that what scientific discovery reveals is not that members of a single natural species differ with respect to their real essences, but that they simply do not belong to the same species; what science shows is there are two (or more) species where we had believed there to be only one. When interpreted as an argument against natural species, it simply begs the question.

But Locke does not make this argument. What entitles him to the seemingly questionable premise is that he is assuming that individuals belong to the same de facto species, not that they belong to the same natural species. And this is not something that is refuted by scientific investigation. It is simply an empirical observation about language use. Locke is arguing that in ordinary discourse we often use a single term to refer to members of a single species. In doing this we assume that they have the same real essences. However, scientists often discover that the individual members have widely different qualities. Consequently, our de facto species are not determined by their real essences; instead, our classifications are based upon those empirical qualities that we happen to take notice of.

That Locke is making an argument regarding de facto and not real species is made plain at the start of the passage. There he employs two qualifiers to signal this to the reader. He says that it

${ }^{24}$ See for instance Christopher Conn, 'Locke on Natural Kinds and Essential Properties', Journal of Philosophical Research 27, (2002): 475-97, at 489. 
is 'the Species of Things to us, [that are] are nothing but the ranking them under distinct Names, according to the complex Ideas in $u s^{\prime} .{ }^{25}$ Likewise, at the end of the passage he does so again, saying, that it is 'the Essence to us, which determines every particular to this or that Classis'. ${ }^{26}$ When interpreted this way, Locke's argument no longer begs the question. In fact, it appears correct.

Finally, consider an argument Locke makes in III. iii. 13. Here he argues that species are the workmanship of the understanding. It is often assumed that he is offering an argument against the existence of natural species. ${ }^{27}$ A closer reading reveals different. Locke writes:

I would not here be thought to forget, much less to deny, that Nature in the Production of Things, makes several of them alike: there is nothing more obvious, especially in the Races of Animals and all Things propagated by Seed. But yet, I think we may say the sorting of things under Names, is the Workmanship of the Understanding [...] And what are the Essences of those Species, set out and marked by Names, but those abstract Ideas in the mind; which are, as it were, the bonds between particular Things that exist and the Names they are to be ranked under? And when general Names have any connexion with particular Beings, these abstract Ideas are the Medium that unites them: so that the Essences of Species, as distinguished and denominated by us, neither are, nor can be any thing but those precise abstract Ideas we have in our minds. And therefore the supposed real Essences of Substances, if different from our abstract Ideas, cannot be the Essences of the Species we rank Things into (my underlining).

Locke offers four separate qualifications to his use of 'species'. These specify that he is referring to classifications that have

${ }^{25}$ Essay, III. vi. 8, 443, my underlining.

${ }^{26}$ Ibid., my underlining.

${ }^{27}$ As by Nicholas Jolley, Locke: His Philosophical Thought (New York, 1999), 149; E.J. Lowe, Locke on Human Understanding (New York, 1995), 162; Walter Ott, Locke's Philosophy of Language (New York, 2004), 71. 
names and are used 'by us'. Locke's argument is not that natural species are the workmanship of the understanding, but that species 'under Names' are. That is, our de facto species are not regulated by nature.

\section{Conclusion}

I have argued that Locke uses 'species' to refer to both natural and de facto species, and that the latter can be identified through the use of various qualifiers. These qualifiers can be found throughout his discussions of species. My analysis reveals that several of Locke's arguments that are often cited as attacks against natural species are in fact concerned with de facto species instead. This, of course, is not to say as much of Locke's arguments. Many do address natural species. Whether or not these culminate in a full-blown denial of natural kinds, I leave for others to consider. What I hope to have provided is a way to better distinguish these separate lines of argument. No doubt, it will remain unclear whether some arguments are against natural or de facto species. These will have to be handled on a case-bycase basis. However, if what I have said is correct, there are far more instances where Locke discusses de facto species than previously thought. This is an important and, in several cases, quite surprising result. Recognizing this helps to fill out our understanding of Locke's treatment of species and frees him from some difficulties that he may have otherwise been charged with.

Before concluding I would like to say a word or two about why Locke may have found it important to argue that de facto species do not mirror natural species, since this is something some readers may find odd. While it may be commonplace nowadays to assume that our linguistic divisions are markedly different than those provided by nature, this was not so in Locke's day. Then it was often assumed that our pre-theoretical taxonomies are basically correct. One obvious reason, then, that Locke had for arguing against de facto species was simply to dispel his contemporaries of this false assumption. 
But there is also a much more fundamental challenge to be met. One of the main themes of Book III is that language is a barrier to clear thought, that it is imperfect and often abused. For this reason, Locke takes it upon himself to help clarify philosophical jargon and to remove all insignificant forms of speech ('rubbish' as he called it) in order to pave the way for a clear and stable science. This is part of his role as 'underlabourer'. In this persona, he sought to impress upon his readers the conventional nature of language. He worried that many of his contemporaries believed that ordinary language more or less mirrors natural species and is regulated by them. For these contemporaries, one job of natural science is to more precisely refine the ideas and language we use to capture these natural joints. Locke, in contradistinction, maintained that the signification of words is not regulated by nature, but is entirely conventional. By emphasizing that our de facto species do not mirror natural joints, Locke showed that ordinary language is no guide to understanding nature and our pre-theoretic classifications cannot figure in genuine natural history. Given the importance of his janitorial project, it should come as no surprise that Locke would have spent considerable time on the nature of language and our de facto species.

James Madison University 